\title{
The Government Responsibility and Function in the New Medical Reform
}

\author{
Na Wang \\ Department of Anesthesiology \\ The First Hospital of Jilin University \\ Changchun, China \\ wangna080613@163.com
}

\author{
Jinguo Wang* (corresponding author) \\ Department of Urology \\ The First Hospital of Jilin University \\ Changchun, China \\ wangjinguolily@163.com
}

\begin{abstract}
The bright spots in the new reform of health care are fairness and justice, including a preliminary solution to the problem of "difficulty and high cost of health treatment" and serving for the masses of ordinary people, that is to say, the government will place national health care in an important position. Reforming, opening-up and developing economy is the only way to solve this problem. In this process, the government should take the responsibility, carry out the role of market mechanism, and then gradually narrow the gap between the rich and the poor and improve the level of national health.
\end{abstract}

Keywords_government responsibility; medical reform; function

\section{INTRODUCTION}

The problem often these take the public interest of some of the medical and health institutions under the guise of a market economy under the guise of mercenary damage the interests of the people, cause most of the people. Severe damage to a "white angel" and "human soul engineer" the glorious title. Now try to reform from the system, fully embodies the superiority of the socialist system in China. There are many deficiencies need to be improved, towards a fair, just, reasonable ways to improve, the government should have the responsibility, but also give full play to the role of market mechanism, gradually narrow the gap and improve the level of national health, following the path of common prosperity, in order to truly build a harmonious socialist family.

\section{THE NEED FOR NEW REFORM OF HEALTH CARE}

There are many reasons for these problems, its basic reason lies in the knowledge of the nature of the medical and health institutions in transition period is not clear, and grasp the characteristic of medical and health service products, adopted improper medical and health economic policy. Therefore, after entering a new round of medical and health system reform in China, bear the brunt of the reform of medical and health institution, as one of the most critical link in China's new health care reform success or failure. The author from the medical and health institutions of public welfare as a starting point, analysis of medical and health institutions still exist problems, in view of the problem put forward the corresponding proposal again [1].
In the medical ethics of scholars believe that the public welfare is based on the interests of all members of the society, make the behavior conform to social accepted moral standards. Public interest theory is mainly refers to the medical staff from the long-term interests of mankind and society, the fair solution in the medical activities of various kinds of interests conflict, make the activities of the medical institution is not only beneficial to the patient, but also to the society, human and future generations. Next, the author from the Angle of public interest theory of Chinese medical and health institutions run, found that there were many problems, this article mainly from the patients, medical staff, medicine, producers and the analysis of the four aspects about the problem of hospital [2].

\section{FAIRNESS AND JUSTICE}

Under the market economic system, "a doctor" difficulty and high cost is a kind of social phenomenon, is also China's role in the development of medical and health cause problems, many experts and scholars have recognized the outstanding problems and reminded the government to attention. But the difficulty and high cost is who's fault? Reason is complex; involve a very wide range of areas.

A lot of Chinese people "see a doctor difficult, expensive" root causes, the author mainly accountability in the government's negligence and lag of medical and health system, and carries on the analysis from the following three aspects.

The medical and health resources allocation is unreasonable, medical and health security system is not perfect. Under the background of market economy system, China's medical and health undertakings of form of system of ownership of a host determines the private hospitals and private clinics, but for large specialized subject hospital, general hospital, they are all forms of public ownership, and even the community hospital and township hospitals most invested by the government. Although the government is encouraging private capital to run a hospital, but the national policies and measures to the development of the non-public sector of the hospital is not perfect, the non-public sector of the hospital and the public sector of the hospital is difficult to equal fair treatment, more than $90 \%$ of the national health resources are blinded by the public sector of the hospital. As a result, the diversification of Chinese medical and health cause do medical pattern has not yet formed, when the government inadequate for medical and 
health undertakings, began to contradictions between supply and demand of health service market [3].

From the medical and health care, medical and health care needs of great unpredictability. In western society, through the institutional arrangements, build system of universal health care, in order to resolve the risk of disease. For the reality of China, no health protection, people have focused on low income or below the poverty line, when encountered greater disease, will naturally look down on disease because of the "expensive". While China's current new rural cooperative medical system in the country, by the end of 2007, the new rural cooperative medical system has been expanded to $86 \%$ of the nation's county, accounting for 726 million farmers, but the farmer's economic co LTD, raise level of ability to pay has been low, the rural medical and health security level is still low [4]. Therefore, the new rural cooperative medical care system can only alleviate the problem of "expensive", and "expensive" problem can't be cured.

\section{THE ROLE OF THE GOVERNMENT IN THIS REFORM}

The government does not enough emphasize on the national health, the drug for medical "and" to the equipment repair medical" problems. With the quickening pace of economic construction, there are a lot of people because of the lack of health knowledge among their citizens, not timely correcting bad habits and sick people proportion bigger and bigger, eventually lead to all these people want to join the" medical care "of the army [5].

Problem has become a problem today and recognized by the medical and health field in China. If the Chinese government to solve the problem to see the doctor as the starting point, the effect is not obvious, natural did not reduce the incidence of a disease. In the western developed countries, the government attaches great importance to the national health promotion, health promotion, make them economic development at the same time, synchronous improve health level.

The government should increase the efforts in publicity and promotion of the national health service which attaches great importance to the health prevention and improve health propaganda and education is the only treatment "difficulty and high cost of the doctor". As China's ongoing reform, although the government for the absolute increase in medical and health institutions, but the proportion of total balance medical institutions is declining [6]. Despite fiscal subsidies relative scale fell sharply, but the government still wants to most. Patients they can in the economic burden of the basic medical and health services.

\section{THE POLICY OF THE GOVERNMENT}

\section{A. The policy of double-track}

Therefore, the government took a price of "double-track". On the one hand require medical institutions provide people with basic medical and health services of the low cost. On the other hand, allows medical institutions by pushing up the price of some of the medical and health services to make up for a lack of development funds. Because of medical and health cause lower barriers to entry, health is more fierce competition, many medical institutions began bought up advanced technology and equipment, in the face of the government fiscal investment in fixed medical institutions only rely on their own business to solve the problem of insufficient funds [7]. Therefore, quite a number of equipment cost need to withdraw from the patients, so, in the Chinese medical and health institutions "to the medicine cure" and "to the equipment repair medical" problem appears is especially outstanding, thus adding to the common people "difficulty and high cost of the doctor" problem.

\section{B. Prevention}

At the same time, the government attaches great importance to the development of public health, highlight the "prevention first" and make all kinds of infectious diseases, endemic diseases have been effectively controlled. So in this period of health concept was defined, and the national basic medical and health care demand and the extension of life expectancy as the core [8].

Market economy period, although the government health input to the whole society level increased significantly, the national comprehensive health indicators have no obvious improvement. National health without proper protection, health rights and interests by market mercilessly deprived.

\section{Definitions of health}

The traditional concept of health is mainly from the perspective of disease to be defined, namely "no disease is healthy and do not meet the requirements of the essence of socialism in China. This is actually a kind of special definition of good health is a kind of ego identity status, are their own personal health experts. According to the traditional concept of health, health is the individual life begins with birth and death process finally time points in health, medical and two unrelated healthy people. This is clearly a narrow concept. Because the concept of health-related at least five: disease, death, doctors, patients, medical [9]. So, in the process of China's new health care reform is necessary to redefine health concept. In Chinese new health care reform stressed that "medical health relationship of hundreds of millions of people health, thousands of happiness." Will health and families, the livelihood of the people of hundreds of millions of people and happiness together. Based on people-oriented, to maintain the rights and interests of the people's health in the first place, to establish people's health services for the purpose of the medicine and health, to establish safeguard people's health to be the center of the medical and health care work, is one of the main tasks of socialist construction. This suggests that need to be redefine health concept in the new period, past cure disease that there was no ill health concept gone, but must put the rights and interests of the people's livelihood, health, happiness, health concept embodied in the new period.

\section{THE GOAL OF THE MEDIAL REFORM, AS WELL AS THE FINAL GOAL OF THE GOVERNMENT}

Health concept to define, for the maintenance of all the people health, improves the level of health of people of all 
ethnic groups has decisive significance. Future new reform process in China, the medical and health care services, not just for solving the problems of the disease-free, late death, but with the echo of physiological needs and social needs of people more humanized service, makes the universal access to effective health care and enjoy the treatment of the humane care and with dignity, no discrimination, social acceptance and approval of no pain, etc. So, it is necessary to redefine health concept in the new period.

To health and health care products attributes to identify clear, from the perspective of economics, according to the analysis of public goods theory, the public health service has a non-exclusive, not crowded and inseparable, belong to the pure public goods. While medical has strong nature of private consumption, consumption can be partitioned, exclusive and crowded, belongs to the quasi-public products.

Theoretically, the pure public goods can only be provided by the government, and quasi-public products can be provided by the government, and can be provided by the market. Health and medical services and, therefore, the government has the natural relation, belong to the scope of the government's public management responsibilities [10]. Of the cause of China's medical and health care, however, the public health service belongs to pure public goods, so, only to be dominated by the government.

\section{CONCLUSIONS}

Government and market division of labor under the planned economy system, the problem of China's medical and health cause completely dominated by the government, not the market participation, makes the medical and health has made remarkable achievements. As the reform and opening up, China has entered a socialist market economy, market economy system further established, the Chinese medical and health cause leading to the way of marketization and commercialization, basically rely on the market from regulation, the duty of the government weakened, the center of gravity of the government's work has completely shifted to economic construction, in the development of medical and health care on the road, there is division of the government and market chaos. So, the author thinks that, the government and market division of labor, the result of the debate on Chinese new healthcare reform and policy has a great deal of influence. So, Chinese new healthcare reform, to China's future reform provides an overall framework, the division of the government and the market problem, control the framework of China's new health care reform, we can easily distinguish clear liability problem.

\section{REFERENCES}

[1] Cutler, D M. Equality, efficiency, and market fundamental: the dynamics of international medical-care reform. Journal of Econometrics. 2002

[2] OECD. The reformof health care: Acomparative analysis of seven OECD countries. 1992

[3] Ufl-G Gerdtham, Bengt Jonsson. "International Comparison of Health Expenditure," Handbook of Health Economics. 2000

[4] Ullrich KHoffmeyer, Thomas R. McCarthy. Finan-cing Health Care. 1994

[5] Designing and Implementing Health Care Provider Payment Systems: How-To Manuals. 2009

[6] Purchasing to improve health systems perform. 2005

[7] John Langenbrunner, Eva Orosz, Joe Kutzin, Miriam Wiley. "Purchasing and Paying Providers". Purchasing to Improve Health Systems Performance. 2005

[8] Public Ends, Private Means: Strategic Purchasing of Health Services. 2007

[9] Slatmean RB Von, Otter C. Planned Markets and Public Competition. 1992

[10] LEIY U, DOUGLAS A. Singh, Essentials of the U S HealthCare System. 2010. 